\title{
Progress in Modern Cataract Surgery - New Steps and Algorithms for Precise Measuring and Intraocular Lens Calculations
}

\author{
Fritz H Hengerer, Gerd U Auffarth and Ina Conrad-Hengerer \\ Department of Ophthalmology, Ruprecht-Karls-University Heidelberg, Germany
}

$\mathrm{n}$ standard cataract surgery, one of the major goals is to reach target refraction. Based on keratometry measurements, axial length and anterior chamber depth, most of the intraocular lens calculation formulae are suitable to achieve this aim. Further evaluation of corneal refractive parameters like anterior and posterior corneal surface by scheimpflug devices led to a significant enhancement of precision in astigmatic and post-refractive surgery cases.

\section{Keywords}

Cataract surgery, intraocular lens (IOL), imaging, corneal refractive power analysis

Disclosure: Fritz H Hengerer, Gerd U Auffarth and Ina Conrad-Hengerer declare no financial interests in the topic mentioned in this article.

Acknowledgements: The authors thank Jörg Iwanczuk from Oculus for technical support.

Compliance with Ethics: This study involves a review of the literature and did not involve any studies with human or animal subjects performed by any of the authors.

Authorship: All named authors meet the Internationa Committee of Medical Journal Editors (ICMJE) criteria for authorship of this manuscript take responsibility for the integrity of the work as a whole, and have given final approval to the version to be published.

open Access: This article is published under the Creative Commons Attribution Noncommercial License, which permits any non-commercial use, distribution, adaptation and reproduction provided the original author(s) and source are given appropriate credit.

Received: 27 October 2017

Accepted: 8 December 2017

Citation: European Ophthalmic Review, 2017;11(2):95-8

Corresponding Author: Ina Conrad-Hengerer,

Department of Ophthalmology, Ruprecht-Karls-University Heidelberg, Im Neuenheimer Feld 400, 69120 Heidelberg, Germany. E: mail@augenarzt-trebur.de

Support: The publication of this article was supported by Oculus.
Cataract surgery had undergone major improvements in different areas over the last 10 years. New intraocular lens (IOL) designs and fourth generation IOL formulae are available, allowing spectacle independence for many patients. Femtosecond laser-assisted cataract surgery (FLACS) has been introduced, and the options seen on television and web-based sources have increased patients' understanding and raised their expectations. Cataract surgeons, as well as the manufacturers of optical biometers and diagnostic equipment, recognized this and consider the corneal optical conditions and evaluate possible ocular surface diseases.

In naive eyes with senile cataract measurement of basic parameters like axial length (AL), keratometry and anterior chamber depth (ACD) were used to calculate the IOL power prior cataract surgery. Many cataract surgeons recognise these needs today while performing FLACS by: using new aspheric, toric and multifocal IOL designs; minimising incision size; and taking advantage of the new fourth generation IOL calculation formulae. Whilst the aim of this article is not to compare the precision and benefits of new IOL power formulae, this review will look beyond this, while pointing out other sources which may influence the quality of patients' vision. In Table 1, a summary of fourth generation to standard formulae and their applications are listed.

These formulae reduce mean absolute error (MAE), meaning more patients achieve final results within $0.5 \mathrm{D}, 0.75 \mathrm{D}$ and $1 \mathrm{D}$ of the expected target refraction. But is this still enough to satisfy all patients' expectations today?

Beyond intensive and individual patient consultation with regard to premium IOLs, such as multifocal or multifocal toric IOLS, intensive pre-operative assessment of corneal and retinal conditions is indispensable.

In recent years, many different optical biometers have been launched to provide, besides the basic necessary parameters like AL and anterior keratometry (ant $K^{\prime} \mathrm{s}$ ), additional information such as $A C D$, posterior keratometry (post $K^{\prime} S$ ), total corneal power (TCP) and total corneal refractive power (TCRP), lens thickness (LT), horizontal-white-to-white (HWTW), for IOL power calculation. For an enhanced evaluation of the corneal shape some devices provide topography and tomography. Using this additional information, it is now possible to produce a more precise IOL power calculation and an enhanced preop assessment before performing premium cataract surgery. Table 2 lists the currently available optic biometers.

In our university eye clinic, we are using the latest, to date, optical coherence tomography (OCT), the IOL Master $700^{\circledR}$ (Zeiss, Oberkochen, Germany) and the new Pentacam ${ }^{\circledR}$ AXL (Oculus, Wetzlar, Germany). The Pentacam AXL is a Scheimpflug-based anterior segment tomographer with a built-in optical biometer. The Pentacam has proven to provide precise keratometry of the anterior and posterior corneal surface, which is the key-parameter for accurate IOL power 
Table 1: Common intraocular lens power calculation formulae

\begin{tabular}{|l|l|l|}
\hline Formula & Parameters & Application \\
\hline Barrett formulas & $\begin{array}{l}\text { AL, ant. Virgin eyes K, } \\
\text { ACD, LT, HWTW }\end{array}$ & $\begin{array}{l}\text { Virgin eyes, post LASIK \& RK, } \\
\text { toric IOLS }\end{array}$ \\
\hline Hill RBF & AL, ant K, ACD, LT, HWTW & Virgin corneas \\
\hline Olsen ray-tracing & $\begin{array}{l}\text { AL, ant K, post K, ACD, LT, } \\
\text { HWTW }\end{array}$ & $\begin{array}{l}\text { Virgin eyes, post LASIK \& RK, } \\
\text { toric IOLS }\end{array}$ \\
\hline Holladay 2 & $\begin{array}{l}\text { AL, ant K, EKR65, ACD, LT, } \\
\text { HWTW }\end{array}$ & $\begin{array}{l}\text { Virgin eyes, post LASIK \& RK, } \\
\text { toric IOLS }\end{array}$ \\
\hline Abdulafi-Koch & AL, ant K, ACD, LT, HWTW & Virgin eyes, toric IOLS \\
\hline iAssort & $\begin{array}{l}\text { AL, ant K, post K, ACD, LT, } \\
\text { HWTW }\end{array}$ & $\begin{array}{l}\text { Virgin eyes, post LASIK \& RK, } \\
\text { toric IOLS }\end{array}$ \\
\hline Holladay 1 & AL, ant K & Virgin eyes \\
\hline Haigis & AL, ant K, ACD & Virgin eyes \\
\hline SRK/T & AL, ant K & Virgin eyes \\
\hline Hoffer Q & ant K & Virgin eyes \\
\hline
\end{tabular}

$A C D=$ anterior chamber depth; $A L=$ axial length; ant = anterior; HWTW = horizontal white-to-white; IOLS = intraocular lenses; $K=$ keratometry; LASIK = laser-assisted in situ keratomileusis; $L T=$ lens thickness; post = posterior; $R K=$ radial keratotomy.

Table 2: Available optical biometers

\begin{tabular}{|c|c|c|c|}
\hline Device & Type of device & $\begin{array}{l}\text { Parameters for IOL } \\
\text { power calculation }\end{array}$ & $\begin{array}{l}\text { Additional } \\
\text { Information }\end{array}$ \\
\hline $\begin{array}{l}\text { Galilei G6 } \\
\text { (Ziemer, Port, } \\
\text { Switzerland) }\end{array}$ & $\begin{array}{l}\text { Tomographer } \\
\text { and optical } \\
\text { biometer }\end{array}$ & $\begin{array}{l}\text { AL, ant } K \text {, post } K, T C P \text {, } \\
\text { ACD, LT, HWTW }\end{array}$ & $\begin{array}{l}\text { Topography \& } \\
\text { tomography }\end{array}$ \\
\hline $\begin{array}{l}\text { Pentacam }{ }^{\circledR} \mathrm{AXL} \\
\text { (Oculus, Wetzlar, } \\
\text { Germany) }\end{array}$ & $\begin{array}{l}\text { Tomographer } \\
\text { and optical } \\
\text { biometer }\end{array}$ & $\begin{array}{l}\text { AL, ant } K \text {, post } K, T C P \text {, } \\
\text { ACD, LT, HWTW }\end{array}$ & $\begin{array}{l}\text { Topography \& } \\
\text { tomography }\end{array}$ \\
\hline $\begin{array}{l}\text { Aladdin (Topcon, } \\
\text { Tokyo, Japan) }\end{array}$ & $\begin{array}{l}\text { Topographer } \\
\text { and optical } \\
\text { biometer }\end{array}$ & $\begin{array}{l}\text { AL, ant } \mathrm{K}, \mathrm{ACD}, \mathrm{LT} \text {, } \\
\text { HWTW }\end{array}$ & Topography \\
\hline $\begin{array}{l}\text { Lenstar }^{\circledast} \text { (Haag- } \\
\text { Streit, Köniz, } \\
\text { Switzerland) }\end{array}$ & $\begin{array}{l}\text { Topographer } \\
\text { and optical } \\
\text { biometer }\end{array}$ & $\begin{array}{l}\text { AL, ant } K, A C D, L T \text {, } \\
\text { HWTW }\end{array}$ & $\begin{array}{l}\text { Topography (4 mm } \\
\text { coverage) }\end{array}$ \\
\hline $\begin{array}{l}\text { OA } 2000 \text { (Tomey, } \\
\text { Aichi, Japan) }\end{array}$ & $\begin{array}{l}\text { Topographer } \\
\text { and optical } \\
\text { biometer }\end{array}$ & $\begin{array}{l}\mathrm{AL} \text {, ant } \mathrm{K}, \mathrm{ACD}, \mathrm{LT} \text {, } \\
\text { HWTW }\end{array}$ & Topography \\
\hline $\begin{array}{l}\text { IOL Master } \\
500^{\circledR} \text { (Zeiss, } \\
\text { Oberkochen, } \\
\text { Germany) }\end{array}$ & $\begin{array}{l}\text { Optical } \\
\text { biometer }\end{array}$ & $\begin{array}{l}\text { AL, ant } \mathrm{K}, \mathrm{ACD}, \mathrm{LT} \text {, } \\
\text { HWTW }\end{array}$ & \\
\hline $\begin{array}{l}\text { IOL Master } \\
700^{\circledR} \text { (Zeiss, } \\
\text { Oberkochen, } \\
\text { Germany) }\end{array}$ & $\begin{array}{l}\text { Optical } \\
\text { biometer }\end{array}$ & $\begin{array}{l}\mathrm{AL} \text {, ant } \mathrm{K}, \mathrm{ACD}, \mathrm{LT} \text {, } \\
\text { HWTW }\end{array}$ & \\
\hline Argos & $\begin{array}{l}\text { Optical } \\
\text { biometer }\end{array}$ & $\begin{array}{l}\text { AL, ant } K, A C D, L T, \\
\text { HWTW }\end{array}$ & \\
\hline AL Scan & $\begin{array}{l}\text { Optical } \\
\text { biometer }\end{array}$ & $\begin{array}{l}\text { AL, ant } K, A C D, L T \text {, } \\
\text { HWTW }\end{array}$ & \\
\hline
\end{tabular}

$A C D=$ anterior chamber depth; $A L=$ axial length; ant $K=$ anterior keratometry;

HWTW = horizontal-white-to-white; IOLS = intraocular lenses; $L T$ = lens thickness; post $K=$ posterior keratometry; $T C P=$ total corneal power.

calculation. ${ }^{1-7}$ The latest studies published, demonstrated a perfect correlation of AL measurements performed with IOL Master 500, IOL Master 700 and Pentacam AXL, as well as a high precision of $\mathrm{AL}, \mathrm{ACD}$ and corneal curvature. ${ }^{8,9}$
Figure 1: JENVIS DryEye pre-treatment

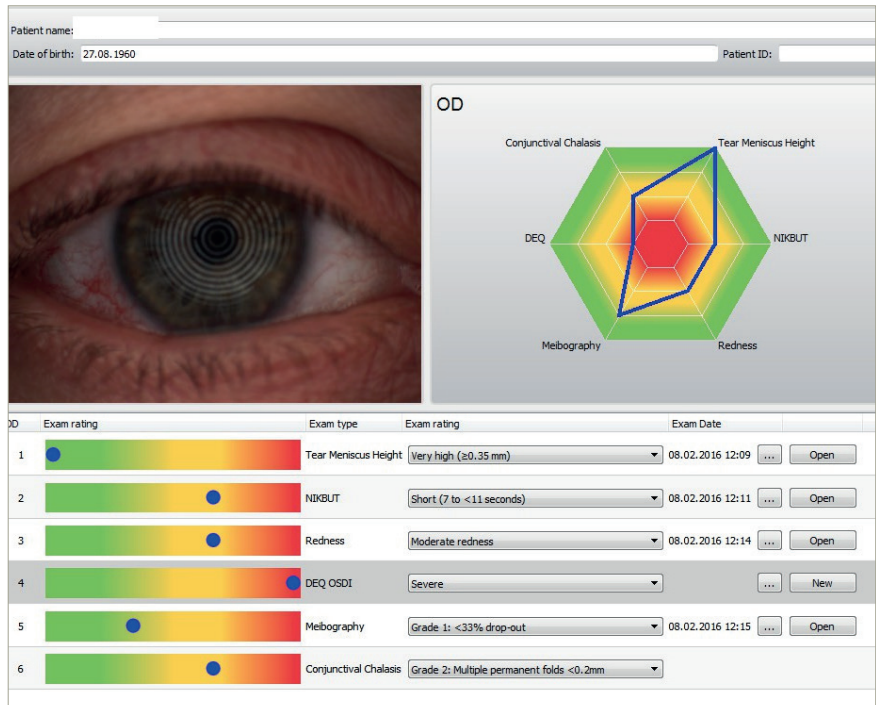

$D E Q=$ Dry Eye Questionnaire; NIKBUT = non-invasive tear film break-up time $O D=$ right eye; $O S D I=$ Ocular Surface Disease Index.

\section{Figure 2: JENVIS Dry Eye post-treatment}

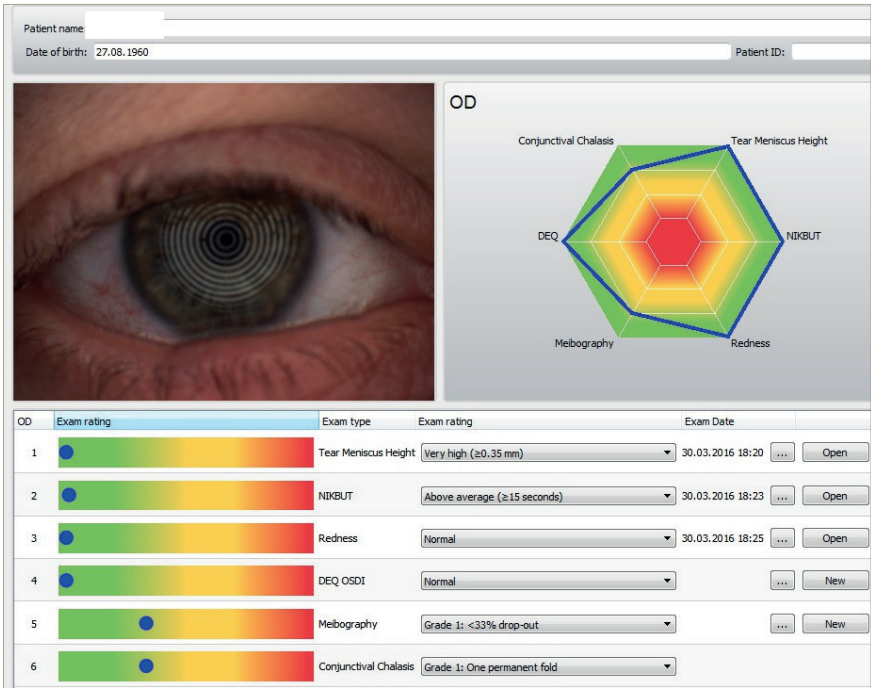

$D E Q=$ Dry Eye Questionnaire; NIKBUT = non-invasive tear film break-up time; $O D=$ right eye; OSDI = Ocular Surface Disease Index.

The main part of our pre-cataract screening routine is focused on objective assessment of the ocular surface, the cornea, anterior chamber and crystal lens conditions. Modern tomographers, like the Pentacam, support us in detecting forme fruste keratoconus (FFKC), past refractive surgery and corneal diseases such as Fuchs endothelial dystrophy, or signs of dry eye prior to cataract surgery.10-17 Assessing the crystaline lens density helps in optimising the settings for femtosecond lasers, ${ }^{18-20}$ in order to reduce the total amount of laser and ultrasonic energy, to reduce the stress for the corneal endothelium, and the surgery time.

For our premium IOL patients we pay high attention to possible ocular surface diseases prior cataract surgery. For many years Schirmer test I and || were used to quantitatively evaluate the amount of tear film. Today this is no longer sufficient. The Schirmer test gives no information about the quality of the tear film, and can be painful for the patients, too. There is common consent that quality of vision is strongly related to ocular surface quality. ${ }^{21-23}$ Sufficient non-invasive tear film break-up 
Table 3: Common intraocular lens power calculation formulae

\begin{tabular}{|c|c|}
\hline Steps & Application and benefit \\
\hline $\begin{array}{l}\text { 1. Check axial } \\
\text { topography } \\
\text { and TCRP map } \\
\text { qualitatively }\end{array}$ & $\begin{array}{l}\text { The benefit of looking at the TCRP map, besides the axial } \\
\text { topography, is the assessment of potential influence of } \\
\text { the posterior corneal surface with regard to total corneal } \\
\text { astigmatism axis, its magnitude, and regularity. }\end{array}$ \\
\hline $\begin{array}{l}\text { 2. Check total } \\
\text { spherical } \\
\text { aberrations Z4.0 }\end{array}$ & $\begin{array}{l}\text { Minimising spherical aberrations, in particular after myopic } \\
\text { corneal refractive surgery. }\end{array}$ \\
\hline 3. Check HOA & $\begin{array}{l}\text { The amount of HOA indicates further parameters like } \\
\text { optical quality of the cornea. Multifocal IOLs are a great } \\
\text { advancement allowing patients to see and perform } \\
\text { without reading glasses, and can offer superior life } \\
\text { quality. However, they are all reducing contrast sensitivity } \\
\text { and quality of vision, which has to be explained to our } \\
\text { patients. But still the question remains, is the corneal } \\
\text { optical quality good enough? Maeda suggested a value of } \\
0.3 \mu \mathrm{m} \text { and below as a cut-off for multifocal IOLs. }{ }^{24}\end{array}$ \\
\hline $\begin{array}{l}\text { 4. Check anterior } \\
\text { corneal astigmatism } \\
\text { and compare to } \\
\text { TCRP }\end{array}$ & $\begin{array}{l}\text { This helps to determine possible differences regarding } \\
\text { the magnitude and axis of the astigmatism. Especially } \\
\text { this part is discussed intensively and many studies have } \\
\text { been published to evaluate the influence of the posterior } \\
\text { surface and possible nomograms avoiding unexpected } \\
\text { surprises after cataract surgery. }{ }^{33-35}\end{array}$ \\
\hline
\end{tabular}

HOA = higher-order aberrations; IOLS = intraocular lenses; TCRP = total corneal refractive power

time (NIBUT), as well as active Meibomian glands, provide the basis for an excellent visual quality outcome after cataract surgery. Moreover, an intuitive summary of the different measurements is key in busy clinical and operative settings. The JENVIS Dry Eye Report, based on the measurements performed with the Keratograph 5K (Oculus, Wetzlar, Germany), is an excellent example on how to present measured values relative to normal data in a clear and easy style. Figures 1 and 2 show a patient with severe ocular surface diseases before and after treatment with dexamethasone eye drops and antibiotic eye drops, as well as Acular ${ }^{\circledast}$ (Allergan, Dublin, Republic of Ireland).

The next challenge is selection of the best-suited IOL for every patient. Therefore, intensive patient consultation helps us understand their habits, their way of living, future plans and, most important, their individual expectations. But can we always satisfy all these?

Sometimes yes, sometimes no. During cataract surgery the crystal lens is removed leaving the cornea as the main optical and refractive part. The assessment of corneal optical quality is one key factor in customised IOL selection. Clinicians and surgeons like and adhere to clear routines. The Cataract Pre-OP Display, developed by Naoyuki Maeda from Japan, is a good example for this. He suggests a four-step screening routine, prior to premium cataract surgery (see Table 3). ${ }^{24}$

IOL calculators should be designed to be intuitive and avoid potential misinterpretation and false entries by the user. Having one IOL calculator providing IOL power calculation formulae for every single imaginable case, is still the dream for cataract surgeons. But manufacturers for such devices have made progress.

Online calculators provided by the manufacturers of toric IOLs are different. Some still use a fixed ratio for the cylinder power at the cornea, and the IOL plane of 1.46, for example. Newer calculators use
Figure 3: Savini toric calculator

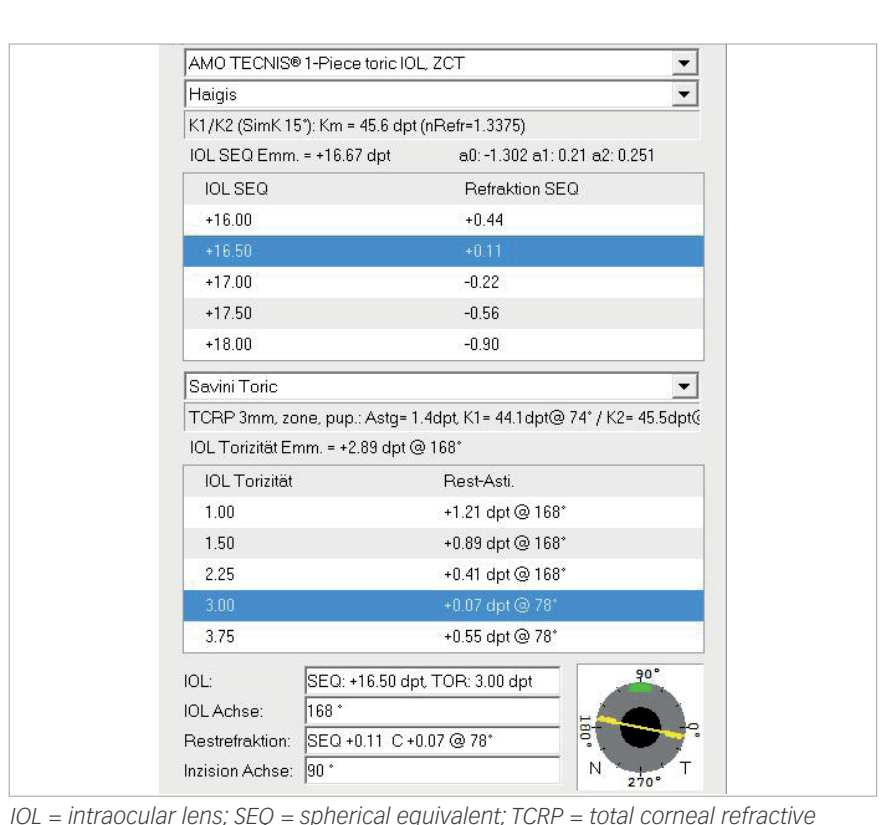
power.

algorithms to estimate the individual effective lens position, others allow entering the data of the posterior cornea and some use nomograms to estimate the net corneal astigmatism like for example the Barrett toric calculator or the Abdulafi-Koch formula. ${ }^{25,26}$ Another growing group of patients are those who have previously undergone refractive surgery such as myopic or hyperopic laser-assisted in situ keratomileusis (LASIK) or photorefractive keratectomy (PRK). For the majority of these patients no data prior to refractive surgery is available. With thanks to Dr Douglas Koch, Dr Warren Hill and Dr Li Wang, the ASCRS online calculator was created and further developed (http://iolcalc.ascrs.org). Using it properly, it offers a solution to many of these patients, including those who underwent radial keratotomy (RK) presenting with highly irregular corneal shape.

The Pentacam AXL includes an IOL calculator that covers all needs in our university clinic, as we have to deal with all kinds of eyes. The standard third generation formulae such as Hoffer Q, Holladay 1, SRK/T and Haigis, and the Barrett Universal 2 are useful for monofocal and multifocal IOL calculations. Since every formula except the Barrett Universal 2 have shown limitations in correct prediction of the expected post-op refraction with regard to $\mathrm{AL}_{1}{ }^{27}$ we should take advantage of the recent ones and compare our standard method and formulae for IOL power calculations, to the latest available formulae.

IOL power calculation for post-refractive patients requires special formulae which are also included in the latest software release of the Pentacam. The known double-K method developed by Aramberri, ${ }^{28}$ and the Barrett True $\mathrm{K}_{1}{ }^{29}$ requires the keratometry prior to surgery, which also requires the spherical equivalent (SEQ) prior surgery, support our daily work if historical data is available. For the majority we are using no-history formulae, such as the PotvinShammasHill, ${ }^{30}$ which is the modified Shammas formula for post-myopic LASIK patients. Although rare, we still encounter patients who have previously undergone RK. Due to loss of any pre-operative refractive data, followed by pure measurement of these highly abnormal corneas, all standard biometers and topographers will often fail. Scheimpflug technology therefore has its benefit. The PotvinHill ${ }^{11}$ formula is a no-history formula and can be used for these patients. Even if the mean error appears relatively low, 
we still have to deal with outliers with +/-0.5 D or +/-1 D, limiting the patient's expectations.

The hottest topic today is toric IOL power calculation. Studies from Fityo et al. ${ }^{32}$ and Koch et al. ${ }^{33}$ have shown the influence of the posterior astigmatism with regard to the total corneal astigmatism. ${ }^{32,33}$ The Savini toric calculator is based on the TCRP, which considers the individually measured posterior cornea. First studies have shown promising outcomes, but further clinical investigation is needed. ${ }^{34,35}$ In large sample studies, ${ }^{34,35}$ the latest formulae such as Barrett toric, ${ }^{25}$ have shown the smallest MAE, and most patients are within the expected post-operative refraction. However, there are still outliers where posterior corneal surface has an influence not present in nomograms.

Figure 3 shows the calculation with the Savini toric calculator for a patient having an astigmatism with the rule. The IOL implanted was an TECNIS ZCT300 (Abbott Medical Optics, Santa Ana, CA, US), with an SEQ of $16.5 \mathrm{D}$. In this particular case the expected post-operative refraction was $0.18 D$ with $-0.07 D$ at $168^{\circ}$. The patient's subjective refraction was plano post-operative.

Pre-operative refractive data for our patients should be available in the operating theatre, ideally paperless. The IOL Calculator provides a readable pdf file for all electronic medical systems (EMR) systems. Its network compatibility allows last-minute calculations as well as the intuitive entry of used IOL data directly after cataract surgery. Moreover, Pentacam AXL can be linked to Leica microscopes (Leica Microsystems
GmbH, Wetzlar, Germany) and True Vision software (TrueVision ${ }^{\circledast}$ Systems Inc., Santa Barbara, CA, US) allowing a superimposition of the implantation axis into the ocular of the microscope, and an eyetracking system based on iris structures or blood vessel recognition. In combination with an eye-tracking system, a more precise toric IOL positioning can be achieved.

We usually see our patients 1 and 4 weeks after surgery. Study patients have to attend more often to have a close follow-up. Careful refraction of our patients is key to track and improve our outcomes. Usually subjective refraction is performed using trial frames or phoropters; however, only evaluation of visual acuity values lacks information about optical quality. The subjective impression is the only parameter, which matters for the patient. During pre-operative conversation patients' expectations can be evaluated and adjusted; however, there may be still some complaints from the patient. To objectively quantify them we exam those patients to evaluate the tear film conditions, and we test contrast sensitivity with and without glare. We found a strong tendency between the tear film quality and contrast sensitivity related to the subjective impression of the patients. Studies are running to understand these relations better.

In conclusion, we would state that advanced pre- and post-operative diagnostic for modern cataract surgery has to go beyond standard biometry, standard tests for dry eye, and subjective refraction. Objective parameters and clinical routines have to be established in order to better meet patients' expectation and provide the best possible way of care for them. $\square$
1. Aramberri J, Araiz L, Garcia A, et al., Dual versus single Scheimpflug camera for anterior segment analysis: precision and agreement, I Cataract Refract Surg, 2012:38:1934-49.

2. Rozema H. Wouters K Mathysen DG, Tassignon MH Overview Rozema JJ, Wouters K, Mathysen DG, Tassignon MJ, Overv of the repeatability, reproducibility, and agreement of the biometry values provided by various op
Am J Ophthalmol, 2014;158:1111-20.

3. Stavridis E, Eppig T, Szentmary N, Reproducibility of Scheimpflus tomography measurements regarding corneal front and back surface power [Article in German], Klin Monbl Augenheilkd 2015;232:1297-30

4. Laursen JV, Jeppesen P, Olsen T, Precision of 5 different keratometry devices, Int Ophthalmol, 2016;36:17-20.

5. Fityo S, Buehren J, Shajari M, et al., Keratometry versus total corneal refractive power: Analysis of measurement repeatability with 5 different devices in normal eyes with low astigmatism, J Cataract Refract Surg, 2016;42:569-76.

6. Hidalgo IR, Rozema JJ, Dhubhghaill SN, et al., Repeatability and inter-device agreement for three different methods of keratometry: Placido, Scheimpflug, and color LED corneal keratometry: Placido, Scheimpflug, and color
topography, J Refract Surg, 2015;31:176-81.

7. Shetty R, Arora V, Jayadev C, et al., Repeatability and agreement of three scheimpflug-based imaging systems for measuring anterior segment parameters in keratoconus, Invest Ophthalmol Vis Sci, 2014;55:5263-8.

8. Sel S, Kaiser D, Kiraly L, Repeatability and agreement of Scheimpflug-based and swept-source optical biometry measurements, Cont Lens Anterior Eye, 2017;40:318-22.

9. Shajari M, Cremonese C, Petermann K, et al., Comparison of axial length, corneal curvature, and anterior chamber depth measurements of 2 recently introduced devices to a known biometer, Am J Ophthalmol, 2017;178:58-64.

10. Alnawaiseh $M$, Zumhagen $L$, Wirths $G$, et al., Corneal densitometry, central corneal thickness, and corneal centratto-peripheral thickness ratio in patients with fuchs endothe dystrophy, Cornea, 2016;35:358-62.

11. Ní Dhubhghaill S, Rozema JJ, Jongenelen S, et al., Normative values for corneal densitometry analysis by Scheimpflug optica values for corneal densitometry analysis by Scheimptiug
assessment, Invest Ophthalmol Vis Sci, 2014:55:162-8.

12. Gilani F, Cortese M, Ambrosio Jr. RR, et al., Comprehensive anterior segment normal values generated by rotating Scheimpflug tomography, J Cataract Refract Surg, 2013;39:1707-12.

13. Belin MW, Villavicencio OF, Ambrósio, Jr. RR, Tomographic parameters for the detection of keratoconus: suggestions for screening and treatment parameters, Eye contact Lens, 2014:40:326-30.

14. Villavicencio OF, Gilani F, Henriquez MA, et al., Independent population validation of the Belin/Ambrósio enhanced ectasia display: implications for keratoconus studies and screening, In J Kerat Ect Cor Dis, 2014;3:1-8.

15. Ambrósio R Jr, Caiado AL, Guerra FP, et al., Novel Pachymetric Parameters Based on Corneal Tomography for Diagnosing Keratoconus, J Refract Surg, 2011;27:753-8.

16. Kim JT, Cortese M, Belin MW, et al., Tomographic normal values for corneal elevation and pachymetry in a hyperopic population, J Clinic Experiment Ophthalmol, 2011,2:130.

17. Feng MT, Belin MW, Ambrosio Jr. R, et al., International values of corneal elevation in normal subjects by rotating Scheimpflug camera, J Cataract Refract Surg, 2011;37:1817-21.

18. Mayer WJ, Klaproth OK, Hengerer FH, Kohnen $\mathrm{T}$, Impact of crystalline lens opacification on effective phacoemulsification time in femtosecond laser-assisted cataract surgery, $\mathrm{Am} J$ Ophthalmol, 2014:157:426-32.

19. Weiner $X$, Baumeister $M$, Kohnen T, Bühren J, Repeatability of lens densitometry using Scheimpflug imaging, J Cataract Refract Surg, 2014;40:756-63

20. Al-Khateeb G, Shajari M, Vunnava K, et al., Impact of lens densitometry on phacoemulsification parameters and usage of ultrasound energy in femtosecond laser-assisted lens surgery, Can J Ophthalmol, 2017;52:331-7.

21. Yu Y, Hua H, Wu M, et al., Evaluation of dry eye after femtosecond laser-assisted cataract surgery, I Cataract Refract Surg, 2015;41:2614-23.

22. Finis $D$, Ackermann $P$, Pischel $N$, et al., Evaluation of meibomian gland dysfunction and local distribution of meibomian gland atrophy by non-contact infrared meibography, Curr Eye Res, 2015:40:982-9.

23. Menzies $\mathrm{KL}$, Srinivasan S, Prokopich $\mathrm{CL}$, Jones L, Infrared imaging of meibomian glands and evaluation of the lipid layer in Sjögren's syndrome patients and nondry eye controls, Invest Ophthalmol Vis Sci, 2015:56:836-41.

24. Maeda N, Assessment of corneal optical quality for premium IOLs with Pentacam, Highlights of Ophthalmology, 2011:39:2-5.

25. Abulafia A, Barrett GD, Kleinmann G, et al., Prediction of refractive outcomes with toric intraocular lens implantation, refractive outcomes with toric intraocular
J Cataract Refract Surg, 2015:41:936-44.

26. Abulafia A, Koch DD, Wang L, et al., New regression formula for toric intraocular lens calculations, J Cataract Refract Surg, 2016;:42:663-71

27. Abulafia A, Barrett $G D$, Rotenberg M, et al., Intraocular lens power calculation for eyes with an axial length greater than $26.0 \mathrm{~mm}$ : comparison of formulas and methods, $I$ Cataract Refract Surg, 2015;41:548-56.

28. Aramberri J, Intraocular lens power calculation after corneal refractive surgery: double-K method, J Cataract Refract Surg, 2003;29:2063-8

29. Abulafia A, Hill WE, Koch DD, et al., Accuracy of the Barrett True-K formula for intraocular lens power prediction after laser in situ keratomileusis or photorefractive keratectomy for myopia, J Cataract Refract Surg, 2016;42:363-9.

30. Potvin R, Hill W, New algorithm for intraocular lens power calculations after myopic laser in situ keratomileusis based on rotating scheimpflug camera data, J Cataract Refract Surg, 2015;41:339-37

31. Potvin R, Hill W, New algorithm for post-radial keratotomy intraocular lens power calculations based on rotating Scheimpflug camera data, I Cataract Refract Surg, 2013;39:358-65.

32. Fityo S, Bühren J, Shajari M, Kohnen T, Keratometry versus total corneal refractive power: Analysis of measurement repeatability with 5 different devices in normal eyes with low astigmatism, I Cataract Refract Surg, 2016;42:569-76.

33. Koch DD, Jenkins RB, Weikert MP, et al., Correcting astigmatism with toric intraocular lenses: effect of posterior corneal
astigmatism, J Cataract Refract Surg, 2013;39:1803-9.

34. Savini G, Næser K, Schiano-Lomoriello D, Ducoli P, Optimized keratometry and total corneal astigmatism for toric intraocular lens calculation, J Cataract Refract Surg, 2017:43:1140-8.

35. Næser K, Savini G, Bregnhøj, JF, Estimating total corneal astigmatism from anterior corneal data, Cornea, 2017;36:828-33. 